\begin{tabular}{|c|l|}
\hline Title & The role of osteopontin in tendon tissue remodeling after denervation-induced mechanical stress deprivation \\
\hline Author(s) & $\begin{array}{l}\text { Mori, Noriaki; Majima, Tokifumi; I wasaki, Norimasa; Kon, Shigey uki; Miy akawa, Kiy oshi; Kimura, Chiemi; Tanaka, } \\
\text { Kunio; Denhardt, David T.; Rittling, Susan; Minamia, A kio; U ede, T oshimitsu }\end{array}$ \\
\hline Citation & $\begin{array}{l}\text { Matrix Biology, 26(1), 42-53 } \\
\text { https://doi.org/10.1016/.matbio.2006.09.002 }\end{array}$ \\
\hline Issue Date & $2007-01$ \\
\hline Doc URL & http://hdl.handle.net/2115/19102 \\
\hline Type & article (author version) \\
\hline File Information & MB26-1.pdf \\
\hline
\end{tabular}

Instructions for use 


\section{The Role of Osteopontin in Tendon Tissue Remodeling after Denervation-Induced Mechanical Stress Deprivation}

Noriaki Mori ${ }^{a}$, Tokifumi Majima ${ }^{a}$, Norimasa Iwasaki ${ }^{\text {, }}$, Shigeyuki Kon ${ }^{\text {b }}$, Kiyoshi

Miyakawa $^{\text {c, }}$ Chiemi Kimura ${ }^{\text {b }}$, Kunio Tanaka ${ }^{\text {, }}$, David T. Denhardt ${ }^{\text {d }}$, Susan Rittling ${ }^{\text {, }}$

Akio Minami ${ }^{a}$, and Toshimitsu Uede ${ }^{\text {b,* }}$

a Department of Orthopaedic Surgery, Hokkaido University School of Medicine, Sapporo, Japan

b Division of Molecular Immunology, Institute for Genetic Medicine, Hokkaido University, Sapporo, Japan

c Central Laboratory for Research and Education, Asahikawa Medical College, Asahikawa, Japan

d Department of Cell Biology and Neuroscience, Rutgers University, Piscataway, New Jersey 08854

e Department of Genetics, Rutgers University, Piscataway, New Jersey 08855 
Number of text pages (47) and figures (8).

A short running head; Role of OPN in tendon tissue remodeling.

Keywords: Osteopontin; Tendon remodeling; Mechanical stress deprivation; Matrix metalloproteinase-13

* Corresponding author. Division of Molecular Immunology, Institute for Genetic Medicine, Hokkaido University, Kita-15 Nishi-7 Kita-Ku, Sapporo, Hokkaido, 060-0815, Japan. Tel.:

+81 11706 7542. Fax: +81 11706 7542. E-mail: toshi@igm.hokudai.ac.jp (T. Uede). 


\section{Abstract}

It has been shown that musculoskeletal tissues undergo dynamic tissue remodeling by a process that is quite sensitive to the mechanical environment. However, the detailed molecular mechanism underlying this process remains unclear. We demonstrate here that after denervation-induced mechanical stress deprivation, tendons undergo dynamic tissue remodeling as evidenced by a significant reduction of the collagen fibril diameter. Importantly, the transient up-regulation of osteopontin (OPN) expression was characteristic during the early phase of tendon tissue remodeling. Following this dynamic change of OPN expression, matrix metalloproteinase (MMP)-13 expression was induced, which presumably accounts for the morphological changes of tendon by degrading tendon collagen fibrils. The modulation of MMP-13 expression by OPN was specific, since the expression of MMP-2, which is also known to be involved in tissue remodeling, did not alter in the tendons under the absence nor presence of OPN. We also demonstrate that the modulation of MMP-13 expression by OPN is due to the signaling through cell surface receptors for OPN. Thus, we conclude that OPN plays a crucial role in conveying the effect of denervation-induced mechanical stress deprivation to the tendon fibroblasts to degrade the extracellular matrices by regulating MMP-13 expression in tendon fibroblasts. 


\section{Introduction}

Bone and muscle provide mechanical support for movement under gravitational and mechanical stress. The structure, organization, and remodeling of bone and muscle are sensitive to the mechanical environment as evidenced by the bone loss and muscle atrophy in bedridden patients as well as the increase in bone and muscle mass in athletes participating in high impact sports. Tendon tissues connect muscle to bone and allow transmission of forces generated by muscle to bone and provide motion and mechanical support to the joints. As in bone and muscle, mechanical loading improves the tensile strength, stiffness, weight and cross-section area of tendons, and these effects can be explained by an increase in collagen and extracellular matrix synthesis by tendon cells (Kannus et al., 1992, 1997; Majima et al., 1996, 2003). However, the molecular mechanism coupling mechanical stress to tendon tissue remodeling remains unclear.

Osteopontin (OPN), also called early $\mathrm{T}$ lymphocyte activation-1 (Eta-1) or secreted phosphoprotein 1 (Spp1), was originally identified as a noncollagenous matrix protein in bone (Franzen and Heinegard, 1985; Singh et al., 1990). This cytokine and mineral matrix protein plays an important role in a number of physiological and pathological events, 
including tissue repair, regulation of bone metabolism, and inflammation and immunity (Denhardt et al., 2001b; Diao et al., 2004; Liaw et al., 1995; O'Regan and Berman, 2000; Sodek et al., 2000; Uede et al., 1997). Recent studies have shown that OPN is a crucial factor triggering bone remodeling (Asou et al., 2001; Denhardt et al., 2001a; Ishijima et al., 2001; Meazzini et al., 1998; Rittling et al., 1998; Terai et al., 1999). In addition, disorganization of collagen and decreases in collagen type I content were observed in mice lacking OPN in the model of skin incision/wound healing (Liaw et al., 1998). Furthermore, OPN was highly up-regulated during the muscle regeneration process induced by injection of the snake venom, cardiotoxin (Hirata et al., 2003).

Musculoskeletal tissue cells, including osteoblasts, chondrocytes, myoblasts and skin and tendon fibroblasts, arise from differentiated mesenchymal stem cells (Salingcarnboriboon et al., 2003; Sharma and Maffulli, 2005). Thus, the musculoskeletal tissues are categorized as the same functional unit developed from the mesenchymal stem cells. This theoretical background and the data mentioned above led us to hypothesize that OPN could regulate tendon tissue remodeling in response to mechanical stress. To test this hypothesis, a denervation-induced mechanical stress deprivation model of the patellar tendon was used to evaluate the role of OPN during tendon tissue remodeling. The specific objectives of this 
study were 1) to detect OPN protein expression in normal tendon, 2) to examine the kinetics of OPN mRNA expression in the patellar tendon after mechanical stress deprivation, 3) to analyze the fine structure of patellar tendon after mechanical stress deprivation either in the presence or absence of OPN, and 4) to clarify a mechanism underlying OPN-induced tendon remodeling. The results shown in this paper provide the essential information on the role of OPN in musculoskeletal soft tissue remodeling responding to mechanical stress. Furthermore, this knowledge can be applied to the development of novel tactics for the treatment of various musculoskeletal soft tissue diseases involving abnormal tissue remodeling.

\section{Results}

\subsection{Detection of OPN Expression in Tendon Fibroblasts}

In reverse transcriptase-polymerase chain reaction (RT-PCR) analysis, OPN mRNA expression was clearly detected in normal patellar tendon of wild-type (WT) mice, which had been kept under a physiological gravitational environment (Fig. 1A). 
Immunohistochemical analysis demonstrated that OPN protein expression was detected in tendon fibroblasts, which existed in the interstitial space of the tendons of WT mice (Fig. 1B-D). OPN protein expression was not detected in the patellar tendon of osteopontin-deficient $\left(\mathrm{OPN}^{-/}\right)$mice (Fig. 1E). We further examined whether cultured tendon fibroblasts could secrete OPN in vitro. The cultured tendon fibroblasts from the normal patellar tendon secreted significant amounts of OPN protein $(608.7 \pm 86.5 \mathrm{ng} / \mathrm{ml})$ into the culture medium. As expected, no OPN protein was found in culture supernatants of the tendon fibroblasts from mice lacking OPN.

\subsection{Denvervation-Induced Stress Deprivation of Patellar Tendon}

Physical tension of tendon is controlled by contraction of quadriceps femoris muscle, which is innervated by femoral nerve. Thus, it is expected that the contraction of quadriceps femoris muscle can be abolished by transection of the femoral nerve, which leads to mechanical stress deprivation of patellar tendon. Surgery was performed under general anesthesia with pentobarbital sodium via intraperitoneal injection at $25 \mathrm{mg} / \mathrm{kg}$ body weight. A longitudinal skin incision was made over the proximal part of right medial 
thigh. To eliminate the effect of femoral nerve regeneration and inflammation on patellar tendon, a $1.0-\mathrm{cm}$ segment of right femoral nerve was microscopically excised at the inguinal region (Fig. 2A,B). Before the excision of femoral nerve, electromyography showed that the stimuli of right femoral nerve elicited electric activity in right quadriceps femoris muscle. We confirmed that the stimuli of femoral nerve did not elicit the electric activity in quadriceps femoris muscle after denervation. We also examined whether the transection of femoral nerve induces inflammatory reactions in tendon. Histologically, there was no inflammatory cell infiltration in tendon at day 7 (Fig. 2D). This was confirmed by absence of F4/80-positive macrophages in tendon tissues at days 1, 3, 7 and 14 after mechanical stress deprivation (Fig. 2D,E). At day 42 after stress deprivation, we showed that atrophy of right quadriceps femoris muscle was induced (Fig. 2F) as described previously (Zhang et al., 2006). Thus, patellar tendon load is selectively deprived by denervation-induced muscle atrophy. Using this model, we evaluated the role of OPN during the course of tendon tissue remodeling after stress deprivation.

\subsection{Lack of OPN Prevents Stress Deprivation-Induced Decrease in Collagen} Fibril Diameter of Patellar Tendon 
The morphological analysis of tendons by transmission electron microscopy (TEM) demonstrated that the diameter of the collagen fibrils significantly decreased in WT mice at 42 days after the denervation-induced stress deprivation of the tendon, as compared to those of the control contralateral tendon of the same mouse (Fig. 3A). In contrast, in mice lacking OPN, the stress deprivation-induced decrease in diameter of tendon collagen fibril was not detected. At day 42 , the diameter of the tendon collagen fibrils was very similar between the stress deprived right tendon and the left tendon that was still responsive to mechanical stress (Fig. 3A).

To quantify the morphological change of tendon collagen fibrils after stress deprivation, a detailed analysis was performed. Although the distribution of collagen fibril diameters at 42 days after stress deprivation was shifted to smaller diameters in WT mice, no such alteration was found in mice lacking OPN (Fig. 3B). The apparent left shift in the collagen fibril size suggests the loss of large fibers and a gain of small fibers with stress deprivation in WT mice.

In this regard, it should be noted that number of fibrils was not significantly different between stress deprived and control loaded tendons in WT mice (Fig. 4A), indicating that 
appearance of small diameter collagen fibrils newly synthesized may not account for the apparent left shift in the collagen fiber size. In addition, mean collagen fibril diameter and fibril occupation ratio per given area were significantly decreased in stress deprived tendons at day 42 , as compared to those of control loaded tendons $(111.6 \pm 5.2 \mathrm{~nm}$ versus $74.4 \pm 4.6 \mathrm{~nm}$ (Fig. 4B) and $61.2 \pm 2.3 \%$ versus $42.6 \pm 2.7 \%$ (Fig. 4C), respectively). These results indicated that pre-existed collagen fibers were forced to reduce diameter of collagen fibrils in WT mice. It is also possible that control contralateral tendon is subjected to mechanical overloading, which leads to increase of collagen fibril diameter. This overloading may explain the difference in collagen fibril diameter between stress deprived and control loaded tendons. Therefore, we examined whether diameter of collagen fibrils in control tendons differ between before and after stress deprivation. We found that collagen fibril diameter did not differ significantly between day 0 and day 42 tendons (Fig. 4D). Nevertheless, in mice lacking OPN, there were no significant differences in collagen fibril diameter and fibril occupation ratio between stress deprived tendon and control tendon at 42 days (Fig. 4B,C). In order to further clarify the time point when fibril diameter change occurs, we additionally obtained tendons of WT mice at 10 and 20 days post-operation. We found that there was significant differences in collagen 
diameter at 20 days, but not 10 days after operation (Fig. 4B). These data demonstrate that OPN is involved in the process of tendon remodeling after stress deprivation. In order to clarify the mechanism how OPN regulates the process of tendon remodeling, we examined the kinetics of OPN mRNA expression in tendon after unloading.

\subsection{The Kinetics of OPN Gene Expression in Tendon after Denervation-Induced Stress Deprivation}

At days $0,1,3,5,7,14$, and 42 after stress deprivation, the expression of OPN mRNA in patellar tendon was examined. By quantitative real-time PCR analysis, we found that normal tendon expressed OPN mRNA. Importantly, OPN expression was up-regulated at day 1 and day $3(n=3, P<0.001)$ after stress deprivation and then declined significantly at day $5(n=3, P<0.001)$. The level of OPN expression at day 5 was not up-regulated, but rather lower than that of normal tendon $(n=3, P<0.001)$, and it remained suppressed even up to day 42 after stress deprivation. In control contralateral tendon, such dynamic changes in OPN expression were not detected (Fig. 5A). Consistent with these data, we demonstrated that OPN protein expression was detected in normal tendon and tendon 
tissues at day 1 and 3 after stress deprivation. However, at day 5 OPN protein expression was not detected (Fig. 5B).

\subsection{Lack of Significant Contribution of Collagen Synthesis and Apoptosis for the Decrease of Collagen Fibril Diameter of Tendon after Mechanical Stress Deprivation}

OPN might modulate the process of tendon remodeling in various ways. It has been shown that OPN regulates collagen synthesis and accumulation during myocardial remodeling (Trueblood et al., 2001). We therefore tested whether a decrease in collagen synthesis could explain the decrease in collagen fibril diameter in tendon of WT mice after stress deprivation. The real-time PCR analysis demonstrated that collagen mRNA synthesis decreased at days 3 and 14 in both stress deprived tendon and control contralateral loaded tendons, as compared to that in tendon at day 0 (without surgery). However, importantly, the values do not differ significantly between stress deprived tendon and contralateral loaded tendon (Fig. 6A), indicating that the decrease of collagen mRNA synthesis may not account for the decrease in collagen fibril diameter of tendon after stress 
deprivation.

OPN is also involved in the regulation of cell apoptosis(Khan et al., 2002; Weintraub et

al., 2000; Zohar et al., 2004). As shown in Fig. 5A, a dynamic change of OPN expression was observed during the early phase of tissue remodeling in stress deprived tendon. Therefore, we examined for the presence of TUNEL-positive cells at days 0,3 , and 7 after stress deprivation. As shown in Fig. 6B, apoptotic cells were not detected in WT mice. Results suggested that an increase in apoptosis of tendon fibroblasts does not significantly contribute to the decrease in collagen fibril diameter in stress deprived tendon.

\subsection{The Dynamic Regulation of MMP-13 Expression during the Course of Tendon Remodeling after Stress Deprivation}

MMPs play a critical role during the course of tissue remodeling. Among the major factors in the remodeling process, collagenases are considered to predominantly degrade the native interstitial collagens in tendon tissue (Chung et al., 2004; Cunningham et al., 1999; Jain et al., 2002). In addition, it has been shown that OPN negatively and positively regulates MMPs expression (D'Alonzo et al., 2002; Philip et al., 2001; Rangaswami et al., 
2004). Therefore, we analyzed the expression level of the genes encoding collagenase-3

(MMP-13) and as a control, MMP-2 in WT mice. MMP-13 mRNA expression was very low up to day 3 after stress deprivation, and then dramatically increased up to day 14 (20 fold increase at day 14). At day 21, the degree of MMP-13 expression returned to the basal level (Fig. 7A). It should be noted that augmentation of MMP-13 expression was not seen in control contralateral loaded tendons. This dynamic change in gene expression was not found for MMP-2 (Fig. 7A). It should be noted that prior to the augmentation of MMP-13 expression, OPN expression was transiently up-regulated at day 3 and sharply declined thereafter (Fig. 5A). Therefore, we investigated whether OPN was involved in MMP-13 gene expression during tendon remodeling after stress deprivation, by comparing the expression level of MMP-13 in tendons of $\mathrm{WT}$ and $\mathrm{OPN}^{-/-}$mice. First, we performed RT-PCR analysis to detect MMP-2 and MM-13 expression in stress deprived tendons of WT mice and $\mathrm{OPN}^{-/-}$mice. MMP-2 expression at stress deprivation day 14 was not significantly augmented in both WT and $\mathrm{OPN}^{-/}$mice, compared to those at control day 0 . In contrast, MMP-13 expression was augmented at day 14 as expected in WT mice, while this augmentation was not detected in $\mathrm{OPN}^{-/-}$mice (Fig. 7B). To quantitate the level of MMP-13 expression, we carried out real-time PCR analysis. We found that MMP-13 gene 
expression was increased 20.7-fold at day 14 after stress deprivation in WT mice but only 4.1-fold in $\mathrm{OPN}^{-/}$mice (Fig. 7C).

The interpretation of data shown in Figs. 5A and 7A is ambivalent. Naturally, the high concentration of OPN may up-regulate MMP-13 expression. However, one can argue that the sharp decline of OPN concentration is required for the up-regulation of MMP-13 expression. In this scenario, exogenous OPN may down-regulate MMP-13 expression. In order to analyze how OPN regulate MMP expression, we set up an in vitro system using cultured tendon fibroblasts. Cultured tendon fibroblasts secreted OPN as described above and expressed a low level of MMP-13 (Fig. 8A). We assumed that secreted OPN bound to its cell surface receptor on fibroblasts. Importantly, MMP-13 expression was significantly augmented by the addition of synthetic peptides, GRGDS, which interfere with the binding of OPN to its receptor, but not GRGES (Fig. 8A). Furthermore, an anti- $\alpha$ v integrin antibody that interferes with the binding of OPN to its receptor $\alpha_{V} \beta 3$ could also augment MMP-13 expression (Fig. 8A). We also inhibit the interaction of OPN and its integrin receptor by anti-OPN antibody (M5). M5, but not control M3 antibody augmented MMP-13 expression (Fig. 8A). To maximize the OPN-mediated signaling, we added exogenous OPN to the culture and found that the MMP-13 expression by tendon fibroblasts 
was down-regulated by exogenous OPN (Fig. 8A). Cultured tendon fibroblasts of OPN-deficient mice also expressed very low level of MMP-13 (Fig. 8B). Since endogenous OPN-mediated signaling is missing in those cells, we added exogenous OPN to the culture and found that MMP-13 expression was further down-regulated (Fig. 8B). Importantly, the interference of interaction with exogenous OPN and its receptor on fibroblasts of OPN-deficient mice by M5 antibody resulted in significant up-regulation of MMP-13 expression, but not by control M3 antibody (Fig. 8B). Taken together, OPN negatively regulated MMP-13 expression through its integrin receptor.

\section{Discussion}

This study demonstrated that, after denervation-induced stress deprivation, tendons underwent dynamic tissue remodeling as evidenced by the significant reduction of the constituent collagen fibril diameter. However, in the absence of OPN, such morphological alterations were not evident. Our results indicate that OPN plays a crucial role in regulating tendon remodeling induced by stress deprivation. It should be noted that augmentation of OPN mRNA expression lasted only for 3 days, indicating that OPN is 
involved in the initial early molecular events during the course of tendon remodeling. Since tendon is categorized as the same functional compartment, including bones and muscles, and shares the common stem cells with these tissues, our findings are consistent with the previous reports, where OPN gene expression was detected in early phases of bone remodeling and muscle regeneration (Denhardt et al., 2001a; Hirata et al., 2003; Nomura and Takano-Yamamoto, 2000; Terai et al., 1999). The tissue remodeling involves both degradation of extacellular matrix proteins and synthesis of new matrix components. In addition, denervation-induced stress deprivation results in the reduction of mechanical strength of stress deprived patellar tendon and the reduction of elastic modulus is associated with the up-regulation of interstitial collagenases (MMP-1, -8 and -13) in tendon (Arnoczky et al., 2004; Lavagnino et al., 2005; Majima et al., 2000). Importantly, these collagenases (MMP-1, -8 and -13) are capable of unwinding and degrading type I collagen, the major component ( $>90 \%$ ) of tendon tissue (Chung et al., 2004; Cunningham et al., 1999; Jain et al., 2002). MMP-8 is mainly produced by neutrophils under inflammatory condition (Balbin et al., 1998; Hasty et al., 1990). We showed that our model did not involve neutrophil infiltration into tendons. It has been shown that rodents lack MMP-1 (collagenase-1) gene (Balbin et al., 2001; Henriet et al., 1992; Vincenti et al., 1998). 
Recently OPN has been linked to activation of MMP-2, MMP-3 and MMP-9 (Agnihotri et al., 2001; Fisher et al., 2004; Ogbureke and Fisher, 2004; Philip et al., 2001; Rangaswami et al., 2004), of which only MMP-2 and MMP-9 degrade type IV collagen, but not type I collagen. Therefore, we focused on MMP-13 and tested whether OPN could regulate MMP-13 (collagenase-3) in stress deprived tendon. We found that the mice lacking OPN did not augment MMP-13 expression during the course of tendon remodeling. However, importantly, we demonstrated that stress deprivation induced a transient, but significant up-regulation of OPN expression that preceded the subsequent up-regulation of MMP-13 gene expression in tendon of WT mice. It should be pointed out that collagen diameter thinning in tendon did not occur prior to the elevation of MMP-13 expression. Thus, it is reasonable to speculate that high OPN expression stimulates or is required for the subsequent up-regulation of MMP-13 expression and tendon remodeling. It is important to note that decreased collagen fibril diameter could be at least partially explained by altered collagen assembly in the presence of higher OPN levels in areas of new matrix synthesis in the tendons as reported previously (Liaw et al., 1998). The defected collagen assembly may lead to secretion of excess non-fibrillar (soluble) collagen into the matrix, which them interact with cell surface receptors and cause the up-regulation of MMP-13 as 
it has been shown in chondrocytes (Ronziere et al., 2005).

However, our results argued against above hypothesis. We demonstrated that cultured tendon fibroblasts of WT mice secreted OPN and expressed low levels of MMP-13. It is possible that secreted OPN binds to its receptor expressed by fibroblasts, thereby negatively regulating the expression of MMP gene in autocrine and paracrine fashion. In this regard, it should be pointed out that addition of exogenous OPN down-regulated the MMP-13 expression in cultured tendon fibroblasts of WT mice. Similarly, the addition of OPN to cultured tendon fibroblast of OPN-deficient mice resulted in the down-regulation of MMP-13 expression. Thus, we favored the scenario in which sharp reduction of OPN expression at day 5 after stress deprivation played a critical role in subsequent induction of MMP-13 expression. We reasoned that the reduction of OPN expression in tendon tissue of WT mice made it difficult to maintain the interaction between tendon fibroblasts and OPN in situ, thus inevitably resulting in the abrogation of interaction between OPN and its receptor on fibroblasts. To mimic this environment, we added synthetic peptide GRGDS, which interferes with the interaction of OPN with its receptor, to the cultured fibroblasts of WT mice and found that MMP-13 expression was significantly up-regulated, however, control peptide GRGES was without effect. In accordance with our results, it was 
previously reported that IL-1 stimulated MMP-2 expression in cultured cardiac fibroblasts and this stimulation was significantly reduced by OPN. Importantly, the OPN effect was abrogated by an integrin antagonist, indicating that OPN's interaction with its receptor inhibited IL-1-stimulated MMP expression (Xie et al., 2003). We further demonstrated that the anti- $\alpha$ v integrin antibody, which also interferes with the binding of OPN to its $\alpha v B 3$ integrin receptor, also significantly augmented MMP-13 expression when added to the cultured tendon fibroblasts of WT mice. One may argue that anti-integrin antibodies and antagonistic peptides may activate integrins (Carron et al., 2000; D'Alonzo et al., 2002; Humphries et al., 2005). Therefore, we attempted to inhibit the interaction of OPN and its receptor by using anti-OPN antibodies. We found that anti-OPN antibody (M5), which interferes with the binding to integrin, but not the control antibody (M3), up-regulate MMP-13 expression. It should be reminded that OPN can be specifically recognized by numbers of cell surface receptors including CD44, RGD-recognizing integrins such as $\alpha 5 \beta 1$ and $\alpha v \beta 3$ and non-RGD recognizing integrins such as $\alpha 4 \beta 1$ and $\alpha 9 \beta 1$ (Weber et al., 1996; Uede et al., 1997; Katagiri et al., 1999; Yamamoto et al., 2003; Diao et al., 2004). Other MMPs might be involved in this remodeling process after stress deprivation. The lack of OPN interaction with its receptor, due to the decreased OPN protein expression by 
anti-sense OPN, led to the increased MMP-2 expression in mammary epithelial cells (Ronziere et al., 2005). However, we found that MMP-2 expression did not differ in the absence or presence of OPN during the course of tendon tissue remodeling.

One critical issue that should be discussed here is the rationale why level of MMP-13 expression in cultured fibroblasts of OPN-deficient mice was not significantly higher as compared to those of wild-type fibroblasts if OPN negatively regulated MMP-13 expression. It is possible that cultured fibroblasts of OPN-deficient mice was stimulated by OPN in calf serum in culture, although we changed culture condition to serum-starved condition prior to MMP-13 assay. In accordance with this hypothesis, MMP-13 expression in cultured fibroblasts of OPN-deficient mice was further down-regulated by addition of exogenous OPN. Nevertheless, the abrogation of this interaction by M5 antibody, significantly up-regulated MMP-13 expression in cultured fibroblasts of OPN-deficient mice. More importantly, in vivo MMP-13 expression was up-regulated in tendon of OPN-deficient mice at day 14 after denervation-induced stress deprivation, although this up-regulation was considerably low as compared to those in WT mice. Taken together, these data suggest that the reduction of OPN expression, thus abrogation of pre-existing interaction between OPN and tendon fibroblasts may play a key role during 
tendon remodeling by regulating MMP-13 expression.

Osteopontin could also suppress collagen synthesis or induce fibroblast apoptosis, thereby modulating remodeling process. We demonstrated that collagen synthesis as defined by type I collagen gene expression was significantly reduced in tendon after stress deprivation. However, importantly, the collagen synthesis did not differ significantly between stress deprived tendon and contralateral loaded tendon, indicating that suppression of collagen synthesis may not account for the decrease in collagen fibril diameter after stress deprivation. We were also unable to detect apoptotic cells during the course of tendon remodeling.

Based on these results, we postulate following scenario for tendon remodeling caused by denervation-induced mechanical stress deprivation. Stress deprivation of the tendon initiates dynamic change of OPN expression in fibroblasts, which induces MMP-13 gene expression, resulting in the degradation of the tendon ECM. Thus in tendon remodeling, OPN may act as a transducer of the mechanical stress to the tendon fibroblasts (Denhardt et al., 2001a). It is therefore possible to control the remodeling process of musculoskeletal soft tissues by manipulating OPN local expression or interfering in the interaction of OPN with its receptor. 


\section{Experimental procedures}

\subsection{Animals}

Osteopontin-deficient $\left(\mathrm{OPN}^{--}\right)$mice were generated according to the previous study

(Rittling et al., 1998). Six-week-old male $\mathrm{OPN}^{-/-}$mice backcrossed 9 times to $\mathrm{C} 57 \mathrm{BL} / 6$ mice and age-matched B6 male WT mice were used in the experiments. The animal experiments were carried out in the Institute of Animal Experimentation, Hokkaido University School of Medicine, under the Rules and Regulations of the Animal Care and Use Committee, Hokkaido University School of Medicine.

\subsection{Real-time Quantitative RT-PCR Analysis of OPN, MMP, and Type I Collagen Transcript Expression}

To examine the change of OPN mRNA expression during the course of tissue remodeling, the patellar tendons from the stress deprived right knee in WT mice were removed at day 0, $1,3,5,7,14$, and 42 after surgery. Similarly, the patellar tendons from the control left 
knee in WT mice were removed at day $0,3,7,14$, and 21 . To clarify the alteration of MMP-2, -13, and type I collagen mRNA, the patellar tendons from bilateral knees in WT mice were removed at day $0,3,7,14$, and 21 after surgery. Total RNAs were prepared from patellar tendons, and first-strand cDNA was generated with a First-strand cDNA synthesis kit (Amersham Biosciences, Uppsala, Sweden). Real-time quantitative RT-PCR was performed on LightCycler-FastStart DNA Master SYBR Green 1 Systems (Roche Diagnostics, Basel, Switzerland). The specific primers used in this study were as follows; the sense primer for OPN was 5'-ACGACCATGAGATTGGCAGTG-3' and the anti-sense primer was 5'-TTAGTTGACCTCAGAAGATGA-3'. The sense primer for MMP-2 was 5'-AGATCTTCTTCTTCAAGGACCGGTT-3' and the anti-sense primer was 5'-GGCTGGTCAGTGGCTTGGGGTA-3'. The sense primer for MMP-13 was 5'-CATCCATCCCGTGACCTTAT-3' and the anti-sense primer was 5'-GCATGACTCTCACAATGCGA-3'. The sense primer for type I collagen was 5'-TTTGTGGACCTCCGGCTC-3' and the anti-sense primer was 5'-AAGCAGAGCACTCGCCCT-3'. The sense primer for G3PDH was 5'-ACCACAGTCCATGCCATCAC-3' and the anti-sense primer was 5'-TCCACCACCCTGTTGCTGTA-3'. 
Values in gene expression level of OPN, MMPs, and type I collagen were normalized to those of G3PDH in each tendon sample. For kinetics of gene expression values at day 0 (before surgery) are expressed as 1. Preliminary study indicated that G3PDH gene expression levels were not altered after denervation.

\subsection{Immunohistochemistry}

Four-micrometer-sections of formalin-fixed and paraffin-embedded mouse tendon tissues were made and deparaffined in xylene, treated with $0.3 \%$ hydrogen peroxidase to block endogeneous peroxidase activity. For OPN staining, these sections were then stained with anti-mouse OPN Rabbit IgG (O-17; IBL, Gunma, Japan), followed by a DAKO EnVision+ system (DAKO, Carpinteria, CA) as specified by the manufacturers. For macrophage staining, the sections were stained with anti-macrophage rat monoclonal, F4/80 antibody (Serotec Ltd, Oxford, UK) and then biotinylated anti-rat IgG $(\mathrm{H}+\mathrm{L})$ (Vector Laboratories, Inc., Burlingame, CA). After washing, the sections were treated with $\mathrm{ABC}$ complex (Vector Laboratories, Inc.). Positive staining was visualized by the peroxidase-diaminobenzidine (DAKO, Carpinteria, CA) reaction and the sections were 
counterstained with Meyer`s hematoxylin.

\subsection{Terminal Deoxynucleotidyltransferase-Mediated dUTP End Labeling (TUNEL)}

TUNEL assay was conducted by using an In situ Apoptosis Detection Kit according to the manufacturer's instruction (Takara Bio Inc., Otsu, Japan). Briefly, the sections were incubated with $15 \mu \mathrm{g} / \mathrm{ml}$ proteinase $\mathrm{K}$ for $15 \mathrm{~min}$ at room temperature and then washed with PBS. Endogenous peroxidase was inactivated by $3 \% \mathrm{H}_{2} \mathrm{O}_{2}$ for 5 min at room temperature and then washed with PBS. Multiple fragmented 3'-OH ends in the sections were labeled with digoxigenin-dUTP in the presence of terminal deoxynucleotidyltransferase (TdT) in a humid atmosphere at $37^{\circ} \mathrm{C}$ for $90 \mathrm{~min}$, and then washed with PBS. Peroxidase-conjugated anti-digoxigenin antibody was then reacted with the sections at room temperature for $30 \mathrm{~min}$. Apoptotic nuclei were visualized using the peroxidase-DAB reaction. The sections were then counterstained with methyl green. TUNEL-positive cells in the sections were counted under a light microscope $(\times 200)$. 


\subsection{OPN Protein Secretion}

To determine the secretion of OPN protein from tendon fibroblasts, OPN protein levels in culture supernatant were measured with an OPN ELISA kit (Kon et al., 2000) according to the manufacturer's instructions (IBL, Gumma, Japan). Briefly, patellar tendons of WT mice and $\mathrm{OPN}^{-/}$mice were plated in the medium and cultured for 20 days. Culture supernatants of 2 nd passage fibroblasts $\left(1 \times 10^{4}\right.$ cells $\left./ \mathrm{ml}\right)$ were collected and subjected to an ELISA analysis. Absorbance at $450 \mathrm{~nm}$ was measured with a microplate reader (Bio-Rad, Richmond, CA).

\subsection{Quantitative Analyses by Transmission Electron Microscopy (TEM)}

WT mice and $\mathrm{OPN}^{-/-}$mice were used for this analysis. At 10, 20 and 42 days after femoral nerve transection, the patellar tendons from both knees in each mouse were removed. A $1 \mathrm{~mm}$-thick specimen sliced perpendicular to longitudinal axis of the patellar tendon axis was cut from each block, and fixed in glutaraldehyde and osmium tetroxide. The specimen was dehydrated and embedded in epoxy resin. Ultrathin sections, 
approximately $80 \mathrm{~nm}$, were cut perpendicular to the longitudinal axis of each specimen. The sections were stained with uranyl acetate and lead citrate for transmission electron microscopy (JEM-100CX, Nihon Denshi, Tokyo, Japan). For quantitative analyses, a randomly selected electron micrograph was taken at a final magnification of $\times 30,000$. The diameters of all collagen fibrils in a $4 \mu \mathrm{m}^{2}$ area chosen from each micrograph were measured using an image analysis software (Win Roof; Mitani Corporation, Tokyo, Japan). A histogram of the diameters of the collagen fibrils for each patellar tendon was obtained from summation of the results of the analysis. For each group, an average histogram was made by calculating the histogram data obtained. The ratio of the total cross sectional area of collagen fibrils to the whole visualized area was defined as the fibril occupation ratio, and this value was calculated for each patellar tendon. The fibril occupation ratio, and the number of collagen fibrils in a $1 \mu \mathrm{m}^{2}$ were also measured using image analysis software.

\subsection{Purification of OPN protein}

Chinese hamster ovary $(\mathrm{CHO})$ cells stably transfected with murine OPN cDNA were 
established. Culture supernatant of transfectants was applied to a formyl-cellulofine column (Seikagaku Kogyo, Tokyo, Japan) coupled with purified IgG from rabbit immunized with synthetic peptide, KSRSFQVSDEQYPDATDE (referred to as M3 antibody). Eluted fraction with $0.2 \mathrm{M}$ glycine- $\mathrm{HCl}, \mathrm{pH} 2.5$ was immediately neutralized and dialyzed against PBS and was referred to as mOPN/CHO. OPN concentration was quantified with OPN ELISA kit (IBL, Fujisaki, Japan).

\subsection{Cell Culture of Fibroblasts}

Fibroblasts were isolated from the patellar tendons of $\mathrm{B} 6$ male WT mice and $\mathrm{OPN}^{-/}$mice at various time points after surgery as described previously (Nagineni et al., 1992). The culture medium used in the present study was made from TIL medium (IBL, Gunma, Japan) supplemented with $10 \%$ fetal calf serum. The cells $\left(2 \times 10^{4}\right.$ cells $\left./ \mathrm{ml}\right)$ were serum-starved and GRGDS peptide (100 $\mu \mathrm{g} / \mathrm{ml}$, ASAHI TECHNO GLASS Co., Tokyo, Japan), GRGES peptide (100 $\mu \mathrm{g} / \mathrm{ml}$, ASAHI TECHNO GLASS Co., Tokyo, Japan), anti- $\alpha \mathrm{v}$ integrin antibody (Ab) (RMV7) (50 $\mu \mathrm{g} / \mathrm{ml}$, PharMingen, San Diego, CA), control anti-Rat IgG $(50 \mu \mathrm{g} / \mathrm{ml}$, West Grove, PA), M5 Ab (30 $\mu \mathrm{g} / \mathrm{ml}), \mathrm{M} 3 \mathrm{Ab}(30 \mu \mathrm{g} / \mathrm{ml})$, or mOPN/CHO 
protein $(10 \mu \mathrm{g} / \mathrm{ml})$ was added and incubated for $48 \mathrm{~h}$. Total RNA from cells was extracted and MMP-13 mRNA expression was measured by real-time PCR.

\subsection{Anti-OPN Antibodies}

The M5 Ab was generated by immunizing rabbit with a synthetic peptide, VDVPNGRGDSLAYGLRS, corresponding to the internal sequence of mouse OPN and could inhibit the interaction of OPN with its receptors as described previously (Yamamoto et al., 2003). The M3 Ab does not interfere with the binding of OPN to its receptors.

\subsection{Statistical Analysis}

All data were represented as mean \pm SE. Significant differences between two groups were determined with using an unpaired Student's $t$-test. The significance level was set at 0.05. $* P<0.05$ versus control; ${ }^{* *} P<0.001$ versus control; NS, not significantly different. 


\section{Acknowledgements}

The authors acknowledge the support of grant-in-aid for scientific research from the

Ministry of Education, Culture, Sports, Science and Technology (17659457), grant-in-aid

for New Energy and Industrial Technology Development Organization (03A04002a), and grant-in aid for the Nakatomi Foundation Tokyo, Japan.

References

Agnihotri, R., Crawford, H. C., Haro, H., Matrisian, L. M., Havrda, M. C., and Liaw, L., 2001. Osteopontin, a novel substrate for matrix metalloproteinase-3

(stromelysin-1) and matrix metalloproteinase-7 (matrilysin). J. Biol. Chem. 276, 28261-28267.

Arnoczky, S. P., Tian, T., Lavagnino, M., and Gardner, K., 2004. Ex vivo static tensile based mechanotransduction mechanism. J. Orthop. Res. 22, 328-333.

Asou, Y., Rittling, S. R., Yoshitake, H., Tsuji, K., Shinomiya, K., Nifuji, A., Denhardt, D. T., and Noda, M., 2001. Osteopontin facilitates angiogenesis, accumulation of osteoclasts, and resorption in ectopic bone. Endocrinology 142, 1325-1332. 
Balbin, M., Fueyo, A., Knauper, V., Pendas, A. M., Lopez, J. M., Jimenez, M. G., Murphy, G., and Lopez-Otin, C., 1998. Collagenase 2 (MMP-8) expression in murine tissue-remodeling processes. Analysis of its potential role in postpartum involution of the uterus. J. Biol. Chem. 273, 23959-23968.

Balbin, M., Fueyo, A., Knauper, V., Lopez, J. M., Alvarez, J., Sanchez, L. M., Quesada, V., Bordallo, J., Murphy, G., and Lopez-Otin, C., 2001. Identification and enzymatic characterization of two diverging murine counterparts of human interstitial collagenase (MMP-1) expressed at sites of embryo implantation. J. Biol. Chem. 276, 10253-10262.

Carron, C. P., Meyer, D. M., Engleman, V. W., Rico, J. G., Ruminski, P. G., Ornberg, R. L., Westlin, W. F., and Nickols, G. A., 2000. Peptidomimetic antagonists of alphavbeta3 inhibit bone resorption by inhibiting osteoclast bone resorptive activity, not osteoclast adhesion to bone. J. Endocrinol. 165, 587-598.

Chung, L., Dinakarpandian, D., Yoshida, N., Lauer-Fields, J. L., Fields, G. B., Visse, R., and Nagase, H., 2004. Collagenase unwinds triple-helical collagen prior to peptide bond hydrolysis. EMBO J. 23, 3020-3030.

Cunningham, K. D., Musani, F., Hart, D. A., Shrive, N. G., and Frank, C. B., 1999. 
Collagenase degradation decreases collagen fibril diameters--an in vitro study of the rabbit medial collateral ligament. Connect. Tissue Res. 40, 67-74.

D'Alonzo, R. C., Kowalski, A. J., Denhardt, D. T., Nickols, G. A., and Partridge, N. C., 2002. Regulation of collagenase-3 and osteocalcin gene expression by collagen and osteopontin in differentiating MC3T3-E1 cells. J. Biol. Chem. 277, 24788-24798.

Denhardt, D. T., Burger, E. H., Kazanecki, C., Krishna, S., Semeins, C. M., and Klein-Nulend, J., 2001a. Osteopontin-deficient bone cells are defective in their ability to produce NO in response to pulsatile fluid flow. Biochem. Biophys. Res. Commun. 288, 448-453.

Denhardt, D. T., Giachelli, C. M., and Rittling, S. R., 2001b. Role of osteopontin in cellular signaling and toxicant injury. Annu. Rev. Pharmacol. Toxicol. 41, 723-749.

Diao, H., Kon, S., Iwabuchi, K., Kimura, C., Morimoto, J., Ito, D., Segawa, T., Maeda, M., Hamuro, J., Nakayama, T., et al., 2004. Osteopontin as a mediator of NKT cell function in T cell-mediated liver diseases. Immunity 21, 539-550.

Fisher, L. W., Jain, A., Tayback, M., and Fedarko, N. S., 2004. Small integrin binding ligand $\mathrm{N}$-linked glycoprotein gene family expression in different cancers. Clin. 
Cancer. Res. 10, 8501-8511.

Franzen, A., and Heinegard, D., 1985. Isolation and characterization of two sialoproteins present only in bone calcified matrix. Biochem. J. 232, 715-724.

Hasty, K. A., Pourmotabbed, T. F., Goldberg, G. I., Thompson, J. P., Spinella, D. G., Stevens, R. M., and Mainardi, C. L., 1990. Human neutrophil collagenase. A distinct gene product with homology to other matrix metalloproteinases. J. Biol. Chem. 265, 11421-11424.

Henriet, P., Rousseau, G. G., and Eeckhout, Y., 1992. Cloning and sequencing of mouse collagenase cDNA. Divergence of mouse and rat collagenases from the other mammalian collagenases. FEBS Lett. 310, 175-178.

Hirata, A., Masuda, S., Tamura, T., Kai, K., Ojima, K., Fukase, A., Motoyoshi, K., Kamakura, K., Miyagoe-Suzuki, Y., and Takeda, S., 2003. Expression profiling of cytokines and related genes in regenerating skeletal muscle after cardiotoxin injection: a role for osteopontin. Am. J. Pathol. 163, 203-215.

Humphries, J. D., Schofield, N. R., Mostafavi-Pour, Z., Green, L. J., Garratt, A. N., Mould, A. P., and Humphries, M. J., 2005. Dual functionality of the anti-beta1 integrin antibody, 12G10, exemplifies agonistic signalling from the ligand binding 
pocket of integrin adhesion receptors. J. Biol. Chem. 280, 10234-10243.

Ishijima, M., Rittling, S. R., Yamashita, T., Tsuji, K., Kurosawa, H., Nifuji, A., Denhardt, D. T., and Noda, M., 2001. Enhancement of osteoclastic bone resorption and suppression of osteoblastic bone formation in response to reduced mechanical stress do not occur in the absence of osteopontin. J. Exp. Med. 193, 399-404.

Jain, A., Brennan, F., Troeberg, L., and Nanchahal, J., 2002. The role of matrix metalloproteinases in rheumatoid tendon disease. J. Hand Surg. [Am.] 27, 1059-1064.

Kannus, P., Jozsa, L., Natri, A., and Jarvinen, M., 1997. Effects of training, immobilization and remobilization on tendons. Scand. J. Med. Sci. Sports 7, 67-71.

Kannus, P., Jozsa, L., Renstrom, P., Jarvinen, M., Kvist, M., Lehto, M., Oja, P., and Vuori, I., 1992. The effects of training, immobilization and remobilization on musculoskeletal tissue. Training and immobilization. Scand. J. Med. Sci. Sports 2, 100-118.

Katagiri, Y.U., Sleeman, J., Fujii, H., Herrlich, P., Hotta, H., Tanaka, K., Chikuma, S., 
Yagita, H., Okumura, K., Murakami, M., Saiki, I., Chambers, A., and Uede, T., 1999. CD44 variants but not CD44s cooperate with beta1-containing integrins to permit cells to bind to osteopontin independently of arginine-glycine-aspartic acid, thereby stimulating cell motility and chemotaxis. Cancer Res. 59, 219-226.

Khan, S. A., Lopez-Chua, C. A., Zhang, J., Fisher, L. W., Sorensen, E. S., and Denhardt, D. T., 2002. Soluble osteopontin inhibits apoptosis of adherent endothelial cells deprived of growth factors. J. Cell Biochem. 85, 728-736.

Kon, S., Maeda, M., Segawa, T., Hagiwara, Y., Horikoshi, Y., Chikuma, S., Tanaka, K., Rashid, M. M., Inobe, M., Chambers, A. F., and Uede, T., 2000. Antibodies to different peptides in osteopontin reveal complexities in the various secreted forms. J. Cell Biochem. 77, 487-498.

Lavagnino, M., Arnoczky, S. P., Frank, K., and Tian, T., 2005. Collagen fibril diameter distribution does not reflect changes in the mechanical properties of in vitro stress-deprived tendons. J. Biomech. 38, 69-75.

Liaw, L., Skinner, M. P., Raines, E. W., Ross, R., Cheresh, D. A., Schwartz, S. M., and Giachelli, C. M., 1995. The adhesive and migratory effects of osteopontin are mediated via distinct cell surface integrins. Role of alpha $v$ beta 3 in smooth 
muscle cell migration to osteopontin in vitro. J. Clin. Invest. 95, 713-724.

Liaw, L., Birk, D. E., Ballas, C. B., Whitsitt, J. S., Davidson, J. M., and Hogan, B. L., 1998. Altered wound healing in mice lacking a functional osteopontin gene (spp1).

J. Clin. Invest. 101, 1468-1478.

Majima, T., Marchuk, L. L., Shrive, N. G., Frank, C. B., and Hart, D. A., 2000.

In-vitro cyclic tensile loading of an immobilized and mobilized ligament autograft selectively inhibits mRNA levels for collagenase (MMP-1). J. Orthop. Sci. 5, 503-510.

Majima, T., Yasuda, K., Fujii, T., Yamamoto, N., Hayashi, K., and Kaneda, K., 1996. Biomechanical effects of stress shielding of the rabbit patellar tendon depend on the degree of stress reduction. J. Orthop. Res. 14, 377-383.

Majima, T., Yasuda, K., Tsuchida, T., Tanaka, K., Miyakawa, K., Minami, A., and Hayashi, K., 2003. Stress shielding of patellar tendon: effect on small-diameter collagen fibrils in a rabbit model. J. Orthop. Sci. 8, 836-841.

Meazzini, M. C., Toma, C. D., Schaffer, J. L., Gray, M. L., and Gerstenfeld, L. C., 1998. Osteoblast cytoskeletal modulation in response to mechanical strain in vitro. J. Orthop. Res. 16, 170-180. 
Nagineni, C. N., Amiel, D., Green, M. H., Berchuck, M., and Akeson, W. H., 1992.

Characterization of the intrinsic properties of the anterior cruciate and medial collateral ligament cells: an in vitro cell culture study. J. Orthop. Res. 10, 465-475.

Nomura, S., and Takano-Yamamoto, T., 2000. Molecular events caused by mechanical stress in bone. Matrix Biol. 19, 91-96.

Ogbureke, K. U., and Fisher, L. W., 2004. Expression of SIBLINGs and their partner MMPs in salivary glands. J. Dent. Res. 83, 664-670.

O'Regan, A., and Berman, J. S., 2000. Osteopontin: a key cytokine in cell-mediated and granulomatous inflammation. Int. J. Exp. Pathol. 81, 373-390.

Philip, S., Bulbule, A., and Kundu, G. C., 2001. Osteopontin stimulates tumor growth and activation of promatrix metalloproteinase-2 through nuclear factor-kappa B-mediated induction of membrane type 1 matrix metalloproteinase in murine melanoma cells. J. Biol. Chem. 276, 44926-44935.

Rangaswami, H., Bulbule, A., and Kundu, G. C., 2004. Nuclear factor-inducing kinase plays a crucial role in osteopontin-induced MAPK/IkappaBalpha kinase-dependent nuclear factor kappaB-mediated promatrix 
metalloproteinase-9 activation. J. Biol. Chem. 279, 38921-38935.

Rittling, S. R., Matsumoto, H. N., McKee, M. D., Nanci, A., An, X. R., Novick, K. E., Kowalski, A. J., Noda, M., and Denhardt, D. T., 1998. Mice lacking osteopontin show normal development and bone structure but display altered osteoclast formation in vitro. J. Bone Miner. Res. 13, 1101-1111.

Ronziere, M. C., Aubert-Foucher, E., Gouttenoire, J., Bernaud, J., Herbage, D., and Mallein-Gerin, F., 2005. Integrin alpha1beta1 mediates collagen induction of MMP-13 expression in MC615 chondrocytes. Biochim. Biophys. Acta. 1746, 55-64.

Salingcarnboriboon, R., Yoshitake, H., Tsuji, K., Obinata, M., Amagasa, T., Nifuji, A., and Noda, M., 2003. Establishment of tendon-derived cell lines exhibiting pluripotent mesenchymal stem cell-like property. Exp. Cell Res. 287, 289-300.

Sharma, P., and Maffulli, N., 2005. Tendon injury and tendinopathy: healing and repair. J. Bone Joint Surg. Am. 87, 187-202.

Singh, R. P., Patarca, R., Schwartz, J., Singh, P., and Cantor, H., 1990. Definition of a specific interaction between the early $\mathrm{T}$ lymphocyte activation 1 (Eta-1) protein and murine macrophages in vitro and its effect upon macrophages in vivo. J. Exp. 
Med. 171, 1931-1942.

Sodek, J., Ganss, B., and McKee, M. D., 2000. Osteopontin. Crit. Rev. Oral Biol. Med. 11, 279-303.

Terai, K., Takano-Yamamoto, T., Ohba, Y., Hiura, K., Sugimoto, M., Sato, M., Kawahata, H., Inaguma, N., Kitamura, Y., and Nomura, S., 1999. Role of osteopontin in bone remodeling caused by mechanical stress. J. Bone Miner. Res. 14, 839-849.

Trueblood, N. A., Xie, Z., Communal, C., Sam, F., Ngoy, S., Liaw, L., Jenkins, A. W., Wang, J., Sawyer, D. B., Bing, O. H., et al., 2001. Exaggerated left ventricular dilation and reduced collagen deposition after myocardial infarction in mice lacking osteopontin. Circ. Res. 88, 1080-1087.

Uede, T., Katagiri, Y., Iizuka, J., and Murakami, M., 1997. Osteopontin, a coordinator of host defense system: a cytokine or an extracellular adhesive protein? Microbiol. Immunol. 41, 641-648.

Vincenti, M. P., Coon, C. I., Mengshol, J. A., Yocum, S., Mitchell, P., and Brinckerhoff, C. E., 1998. Cloning of the gene for interstitial collagenase-3 (matrix metalloproteinase-13) from rabbit synovial fibroblasts: differential expression 
with collagenase-1 (matrix metalloproteinase-1). Biochem. J. 331 ( Pt 1), 341-346.

Weber, G.F., Askar, S., Glimcher, M.J., and Cantor, H., 1996. Receptor-ligand interaction between CD44 and osteopontin (Eta-1). Science 271, 509-512.

Weintraub, A. S., Schnapp, L. M., Lin, X., and Taubman, M. B., 2000. Osteopontin deficiency in rat vascular smooth muscle cells is associated with an inability to adhere to collagen and increased apoptosis. Lab. Invest. 80, 1603-1615.

Xie, Z., Singh, M., Siwik, D. A., Joyner, W. L., and Singh, K., 2003. Osteopontin inhibits interleukin-1beta-stimulated increases in matrix metalloproteinase activity in adult rat cardiac fibroblasts: role of protein kinase C-zeta. J. Biol. Chem. 278, 48546-48552.

Yamamoto, N., Sakai, F., Kon, S., Morimoto, J., Kimura, C., Yamazaki, H., Okazaki, I., Seki, N., Fujii, T., and Uede, T., 2003. Essential role of the cryptic epitope SLAYGLR within osteopontin in a murine model of rheumatoid arthritis. J. Clin. Invest. 112, 181-188.

Zhang, D., Liu, M., Ding, F., and Gu, X., 2006. Expression of myostatin RNA transcript and protein in gastrocnemius muscle of rats after sciatic nerve resection. J. Muscle Res. Cell Motil., 1-8. 
Zohar, R., Zhu, B., Liu, P., Sodek, J., and McCulloch, C. A., 2004. Increased cell death in osteopontin-deficient cardiac fibroblasts occurs by a caspase-3-independent pathway. Am. J. Physiol. Heart Circ. Physiol. 287, H1730-1739.

\section{Legends for Figures}

Fig. 1. Expression of OPN in normal patellar tendon in wild-type (WT) mice. (A) Total RNA was isolated from the homogenized samples of 21 patellar tendons from WT mice. RT-PCR shows the expression of OPN mRNA in normal loaded patellar tendon. The RT-PCR for G3PDH was used as a control. The number indicates the relative expression level of OPN mRNA against G3PDH. (B) Immunohistochemical staining of the sections obtained from the patellar tendon tissues of WT mice. (C) Magnified view of OPN-positive fibroblasts in the boxed region in B. (D) Hematoxylin-eosin (HE) staining of respective sections in B. (E) Immunohistochemical staining of the sections obtained from patellar tendon tissues of $\mathrm{OPN}^{-/-}$mice. Scale bars indicate $50 \mu \mathrm{m}$.

Fig. 2. Denervation-induced stress deprivation model of the patellar tendon. 
Macroscopic anatomy of the proximal part of mouse lower extremity. (B) Right panel, an enlarged view of the region in the circled portion in left panel, shows femoral nerve exposed by small incision over the proximal part of the right medial thigh. The femoral nerve was microscopically transected at the inguinal region. (C) Electromyographic investigation to confirm the patellar tendon of denervation-induced stress deprivation. When femoral nerve is stimulated before denervation (upper panel), electrical activity is recorded in the quadriceps femoris muscle, while that is not detected after denervation (lower panel). FN, femoral nerve; Quad, quadriceps femoris muscle. (D) No inflammatory cell infiltration in stress deprived tendon after denervation. HE staining (left) and F4/80 staining (right) of tendon sections at day 7 after stress deprivation. (E) F4/80 staining of tendon sections at day 1, 3, 14 after stress deprivation. Inflammatory synovial tissue of mice was used as a positive control and arrowheads indicate F4/80-positive cells. Scale bars indicate $50 \mu \mathrm{m}$. Data are representative of several independent experiments. (F) Light micrographs of the transverse sectioned quadriceps femoris muscle obtained from WT (left panels) and $\mathrm{OPN}^{-/-}$mice (right panels) at day 42 after stress deprivation. Sections were stained with hematoxylin-eosin (HE). Scale bars indicate $50 \mu \mathrm{m}$. Macroscopic views of right and control left quadriceps muscles in both 
WT and $\mathrm{OPN}^{-/-}$mice were also shown.

Fig. 3. Transmission electron micrographs (TEM) of collagen fibril morphology in normal loaded and stress deprived patellar tendon. (A) Upper panel shows the micrographs of stress deprived patellar tendon (left) and contralateral normal patellar tendnon (right) in WT mice at day 42 after stress deprivation. Lower panel shows micrographs of stress deprived patellar tendon (left) and contralateral normal patellar tendon (right) in $\mathrm{OPN}^{-/-}$mice at day 42. Scale bars indicate $1 \mu \mathrm{m}$. (B) Histogram profiles of the collagen fibril diameter in WT mice $(n=8)$ and $\mathrm{OPN}^{-/-}$mice $(n=10)$ at day 42 .

Fig. 4. Quantitative analyses from ultrastructural observations of patellar tendons in WT mice $\left(n=5,5\right.$, and 8 at day 10,20 and 42 , respectively) and $\mathrm{OPN}^{-/-}$mice $(n=10)$ at day 10 , 20, or 42 after stress deprivation. (A) Number of fibrils $/ \mu \mathrm{m}^{2}$ at day 42 . (B) Mean collagen fibril diameter (nm) at day 10, 20, or 42. (C) Fibril occupation ratio (\%) at day 42. (D) Left panel is preoperative normal loaded patellar tendon and right panel is control patellar tendon at day 42 after surgery in WT mice. Scale bars indicate $1 \mu \mathrm{m} . \quad * P<0.05$ versus day $0 ; * * P<0.001$ versus day $0 ; \mathrm{NS}$, not significantly different. 
Fig. 5. Changes in the expression level of OPN in tendon of WT mice after stress deprivation. (A) Real-time PCR was conducted at indicated times after stress deprivation of the tendon. Expression of OPN mRNA was normalized by G3PDH. Total RNA was isolated from the homogenized samples of ten stress deprived patellar tendons at day $0,1,3$, 5,7 , and 42 after surgery and ten control patellar tendons at day $0,3,7$, and 14 after surgery. $n=3, * * P<0.001$ versus day 0 . (B) Immunohistology of OPN expression by patellar tendon fibroblasts at days $0,1,3$, and 5 after stress deprivation. Arrowheads indicate positive staining. Scale bars indicate $50 \mu \mathrm{m}$.

Fig. 6. Lack of significant contribution of collagen mRNA synthesis and apoptosis for the decrease of collagen fibril diameter after stress deprivation. (A) Real-time PCR analysis of type I collagen mRNA expression in WT mice was conducted at day 0,3 , and 14 after mechanical stress deprivation ( $n=4$, NS, not significantly different). Expression of OPN mRNA was normalized by G3PDH. (B) Terminal deoxynucleotidyltransferase-mediated dUTP end labeling (TUNEL) assay was conducted at day 0, 3, 7 after stress deprivation. Mammary ground tissue in mice was used as a positive control. Arrowheads indicate TUNEL-positive cells. Scale bars indicate $50 \mu \mathrm{m}$. 
Fig. 7. Change of the expression level of MMP-13 and -2 genes in stress deprived tendons of WT mice and $\mathrm{OPN}^{-/}$mice. (A) Real-time PCR analyses of MMP-13 (left panel) and -2 (right panel) mRNA expression in stress deprived and control loaded tendons of WT mice at indicated time points $(n=4, * P<0.05$ versus day 0 . NS, not significantly different). (B) RT-PCR analysis of MMP-13 (left panel) and -2 (right panel) expression at day 0 and day 14 after stress deprivation in both $\mathrm{WT}$ and $\mathrm{OPN}^{-/-}$mice. The numbers indicate the relative expression level of OPN mRNA against G3PDH. (C) Quantitative real-time PCR analysis of MMP-13 mRNA expression in tendon at day 0 day 14 after stress deprivation $(n=4, * P<0.05)$ in both $\mathrm{WT}$ and $\mathrm{OPN}^{-/}$mice.

Fig. 8. Up-regulation of MMP-13 expression by abrogation of interaction between OPN and its receptors. (A) The tendon fibroblasts of WT mice $\left(2 \times 10^{4}\right.$ cells $\left./ \mathrm{ml}\right)$ were cultured under serum-starved conditions with $100 \mu \mathrm{g} / \mathrm{ml} \mathrm{GRGDS,} 100 \mu \mathrm{g} / \mathrm{ml}$ GRGES peptide, 50 $\mu \mathrm{g} / \mathrm{ml}$ anti- $\alpha \mathrm{v}$ integrin antibody, $50 \mu \mathrm{g} / \mathrm{ml}$ control Rat IgG, $30 \mu \mathrm{g} / \mathrm{ml}$ M5 antibody, $30 \mu \mathrm{g} / \mathrm{ml}$ M3 antibody, or $10 \mu \mathrm{g} / \mathrm{ml}$ purified mouse OPN (mOPN/CHO) for $48 \mathrm{~h}$. Total RNA was extracted and MMP-13 mRNA expression was measured by real-time PCR $\left(n=3,{ }^{*} P<\right.$ 0.05 versus control; ${ }^{* *} P<0.001$ versus control; NS, not significantly different). (B) The 
tendon fibroblasts of $\mathrm{OPN}^{-/}$mice $\left(2 \times 10^{4}\right.$ cells $\left./ \mathrm{ml}\right)$ were cultured under serum-starved conditions in the absence or presence of $10 \mu \mathrm{g} / \mathrm{ml}$ purified mouse OPN (mOPN/CHO) for $48 \mathrm{~h}$. In some experiments, $30 \mu \mathrm{g} / \mathrm{ml} \mathrm{M} 5$ or $30 \mu \mathrm{g} / \mathrm{ml} \mathrm{M} 3$ antibody was included in the culture. Total RNA was extracted and MMP-13 mRNA expression was measured by real-time PCR $\left(n=3,{ }^{* *} P<0.001\right.$ versus control). 
A

$\begin{array}{ll}0.15 & (\text { OPN/G3PDH) } \\ & \text { OPN } \\ & \text { G3PDH }\end{array}$

B

D
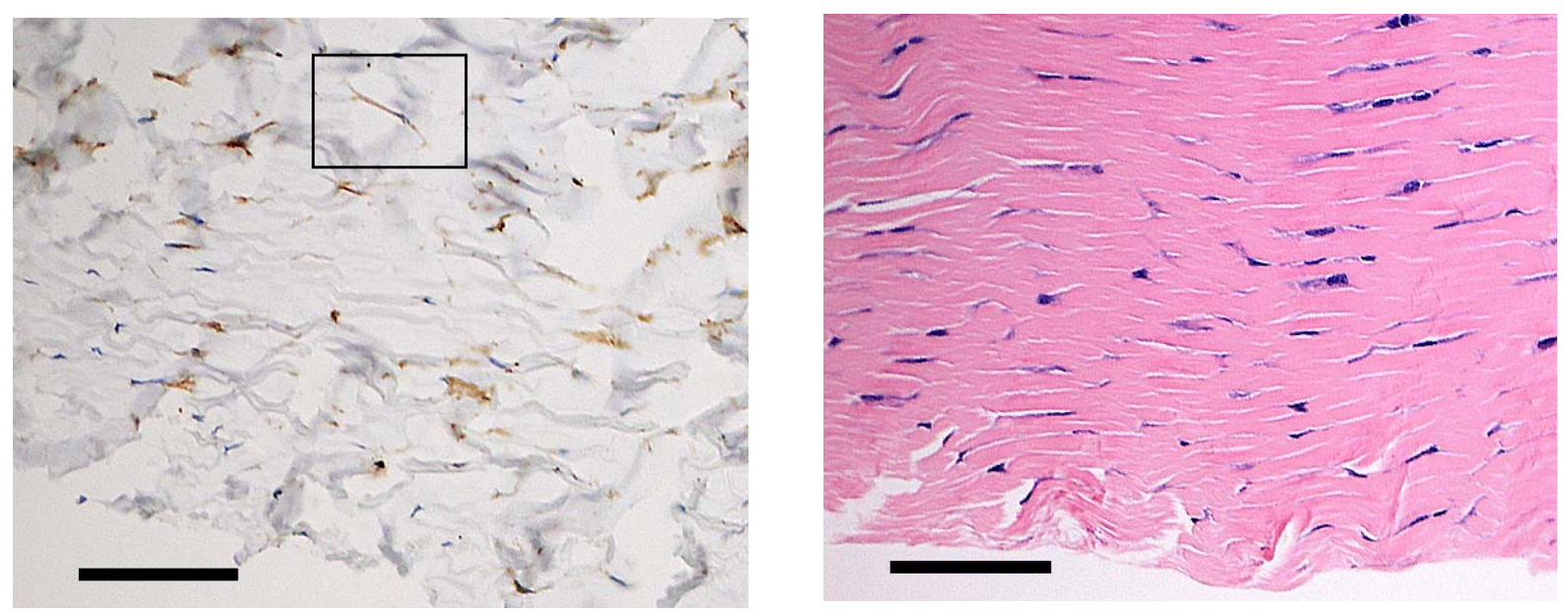

C

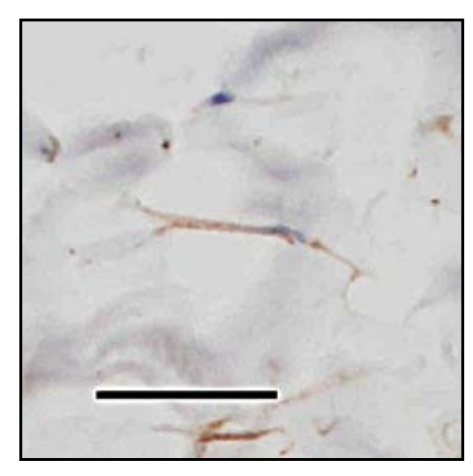

E

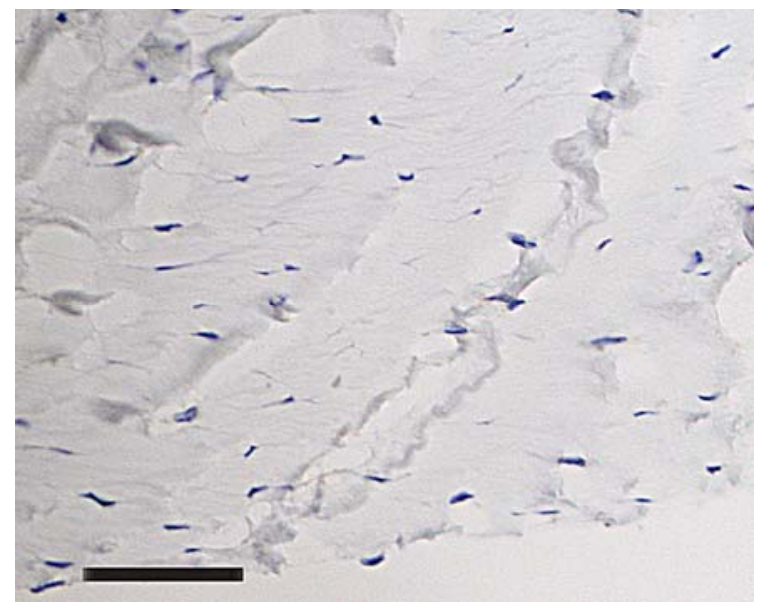




\section{Figure 2}

A

Quadriceps femoris muscle

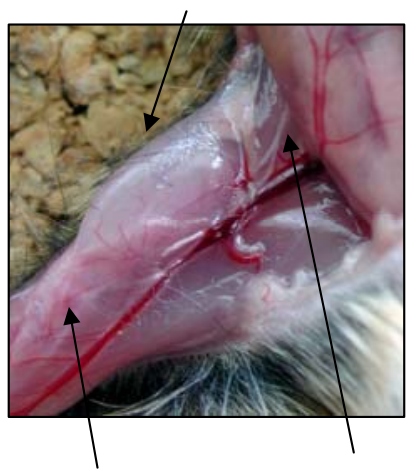

Patellar tendon Femoral nerve

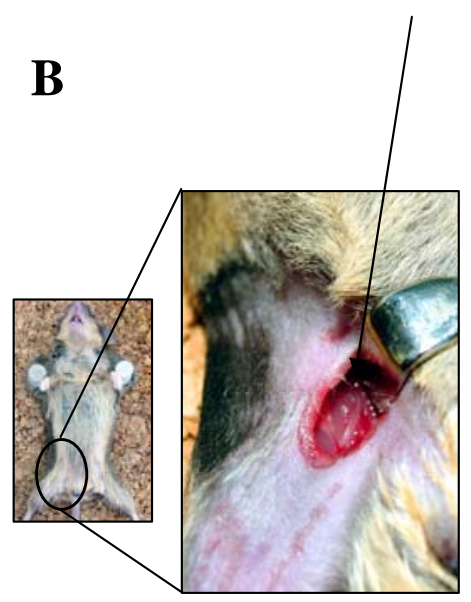

C

\section{Femoral nerve} denervation

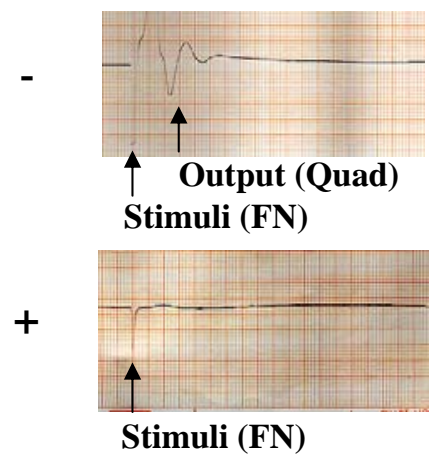

D
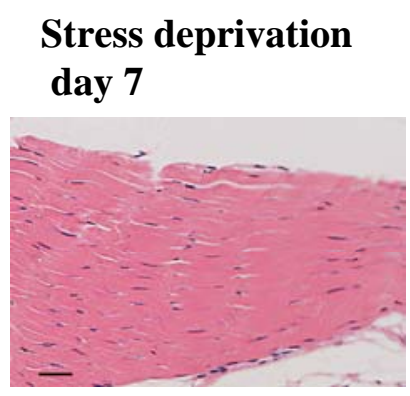

E

\section{Positive Control}

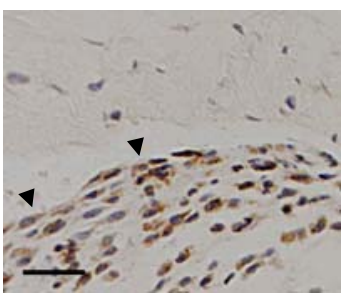

Stress deprivation day 1

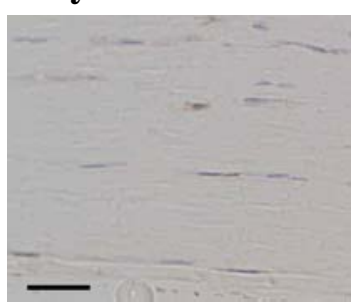

Stress deprivation day 14

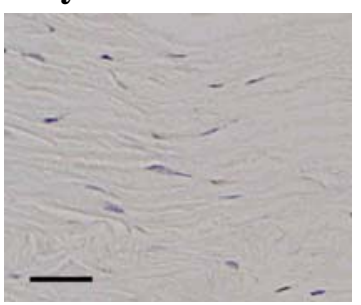

$\mathbf{F}$
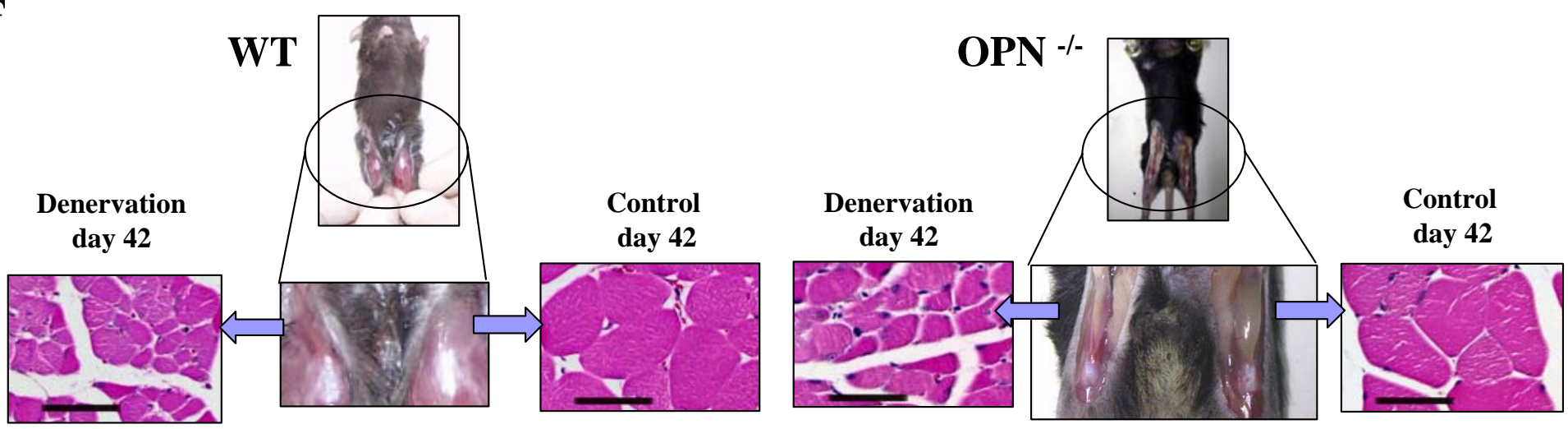
A

Stress deprivation day 42

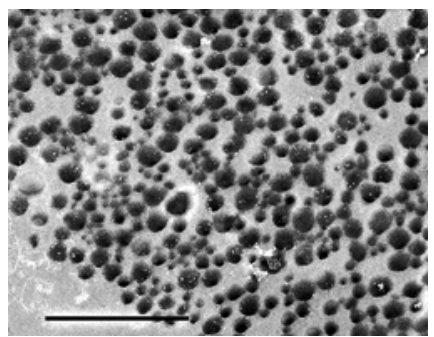

Stress deprivation day 42

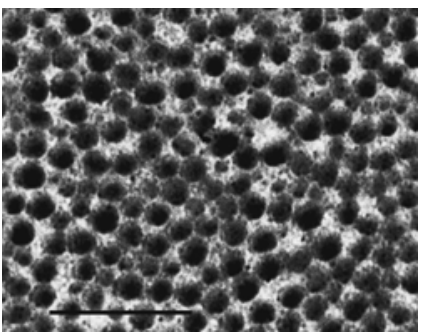

Control day 42

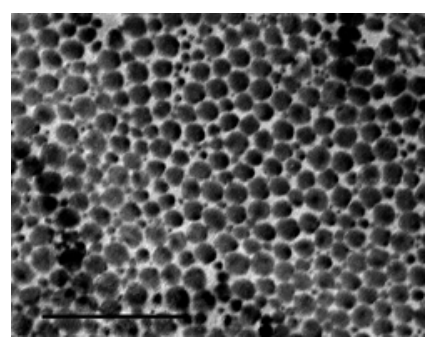

Control day 42

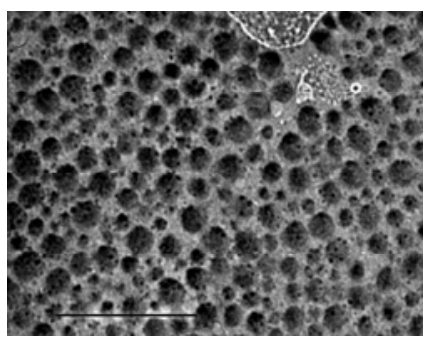

B

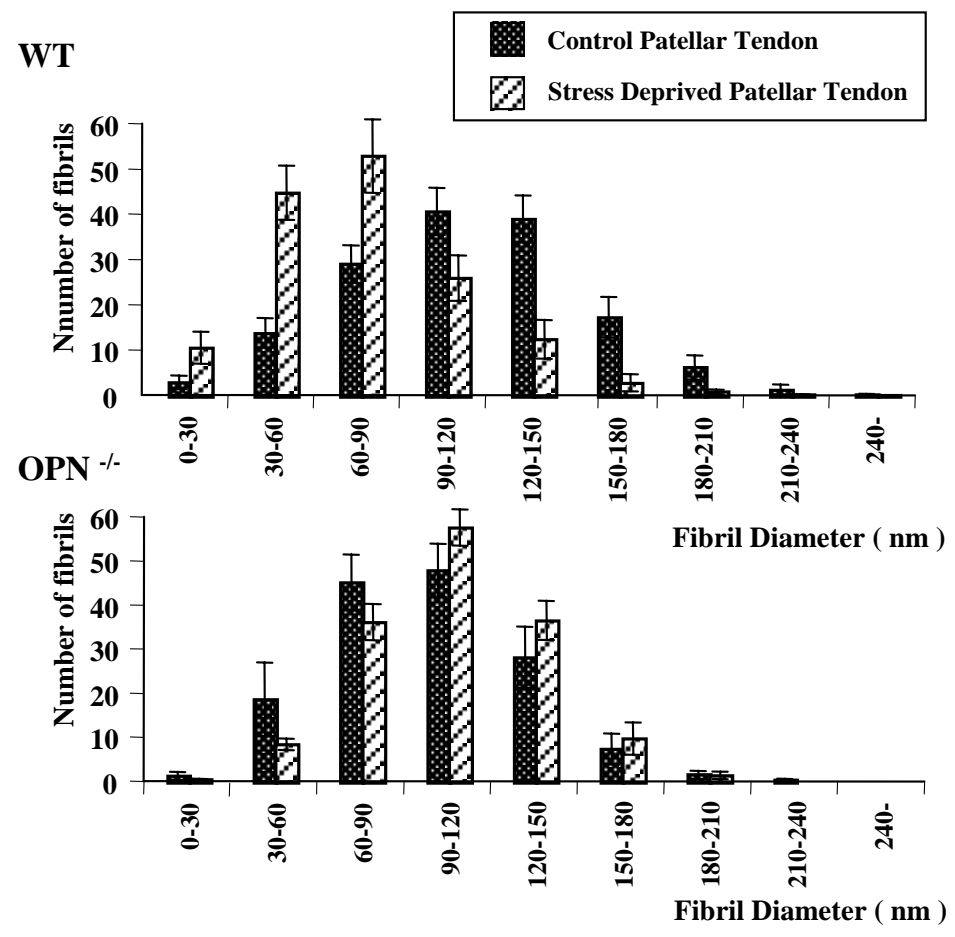


A

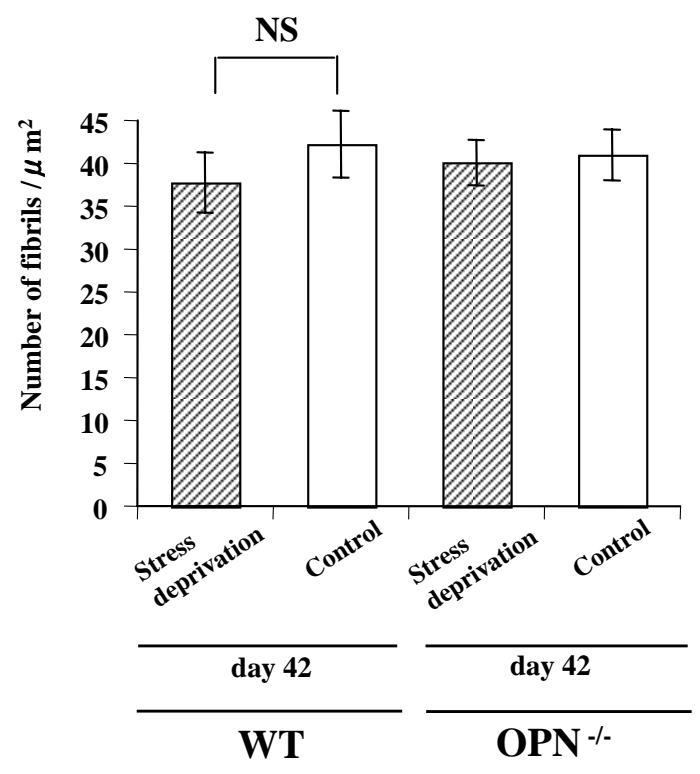

C

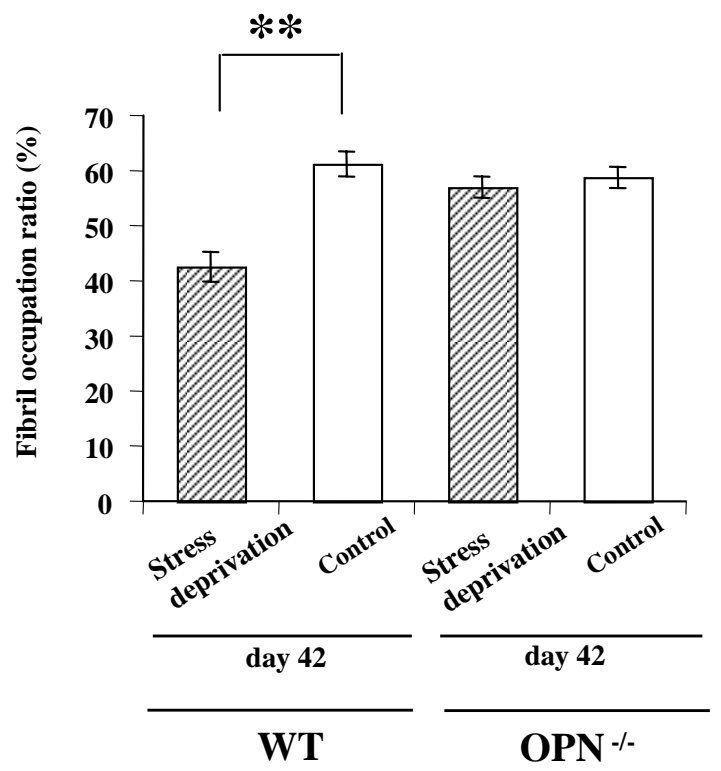

B
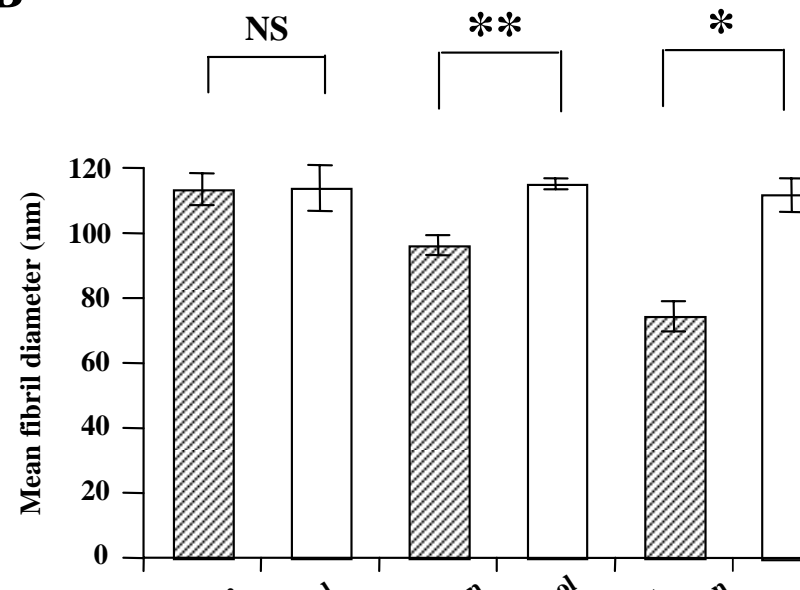

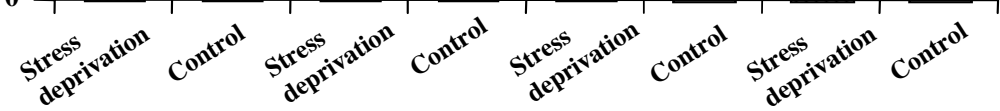

$\frac{\overline{\text { day } 10}}{} \frac{\text { day } 20}{\text { day } 42} \frac{\text { day } 42}{\mathrm{OPN}^{-/}}$

D

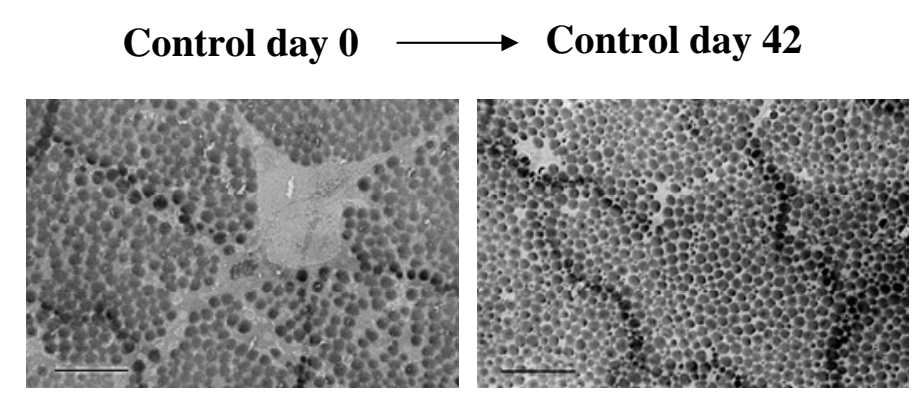

WT 

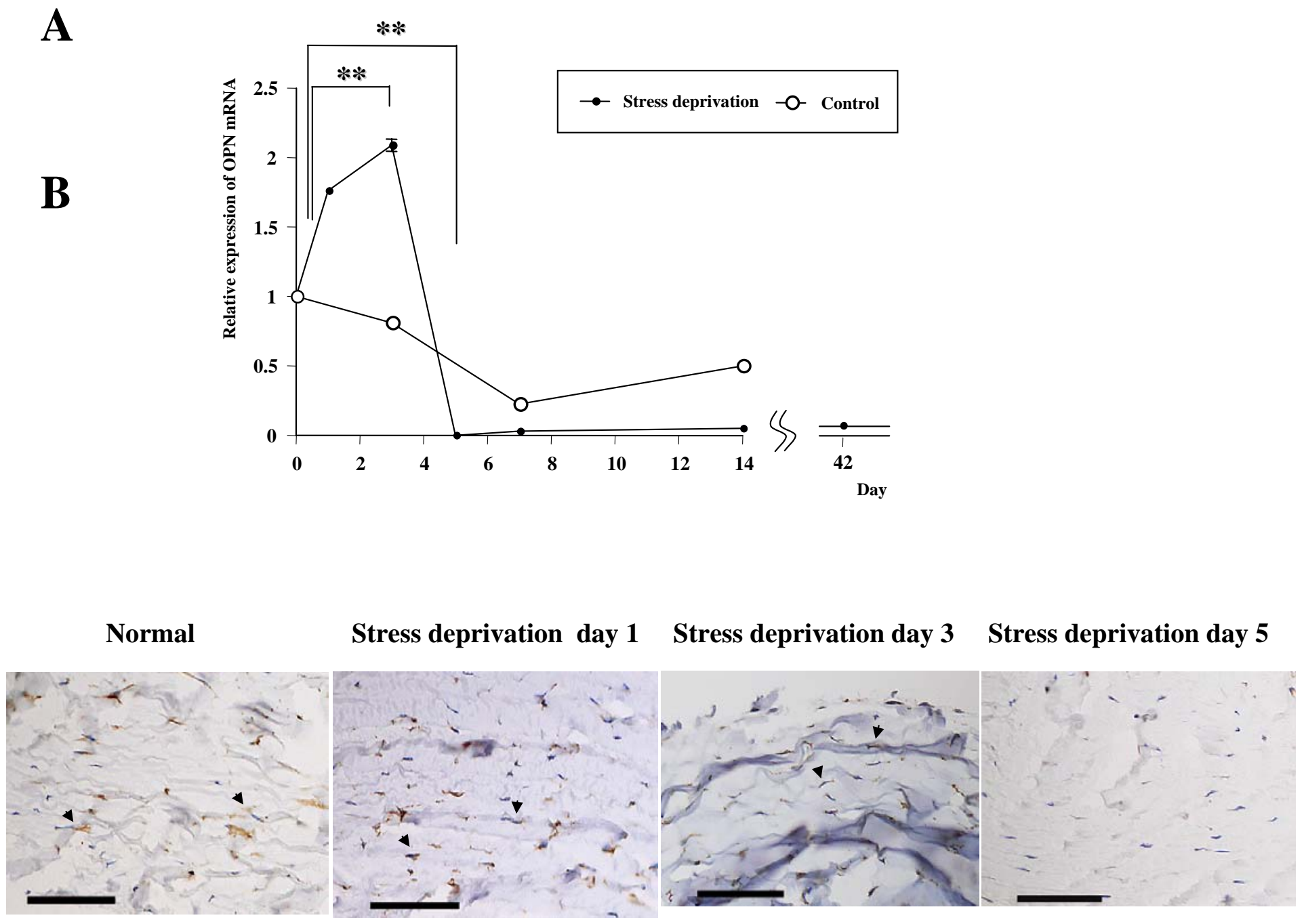
A

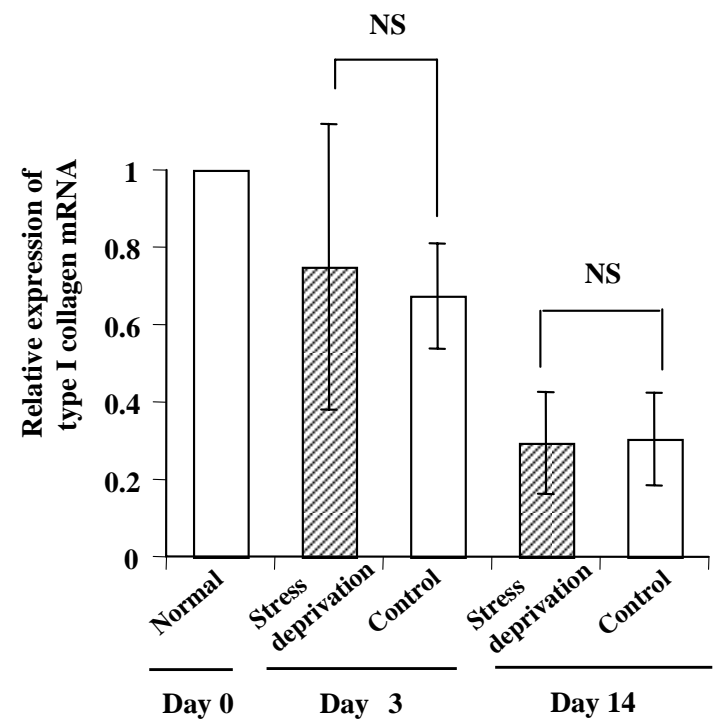

B

Normal

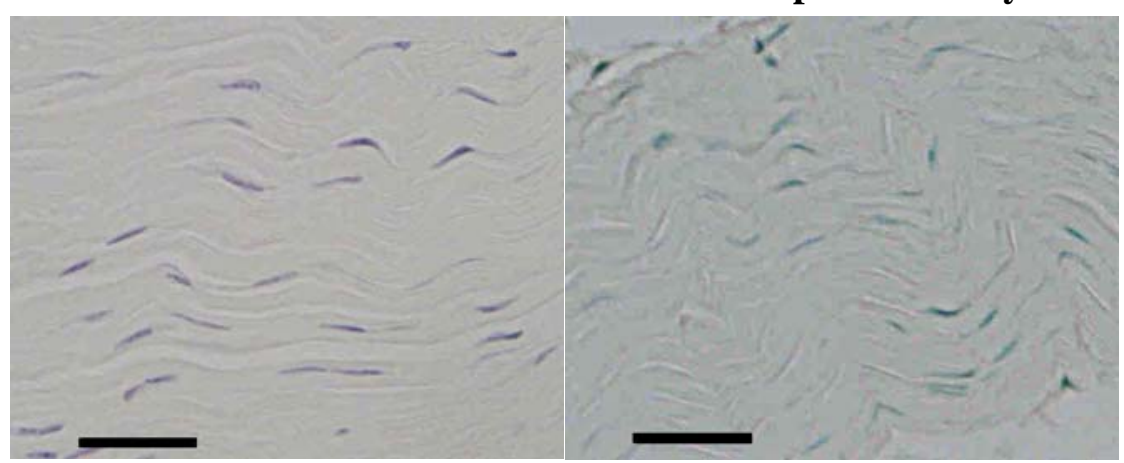

Stress deprivation day 3

Positive Control

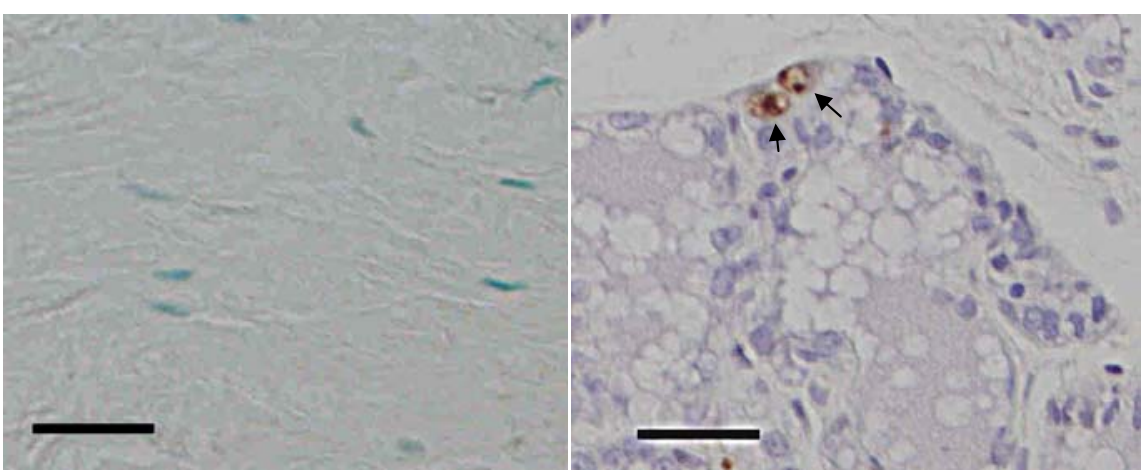


A

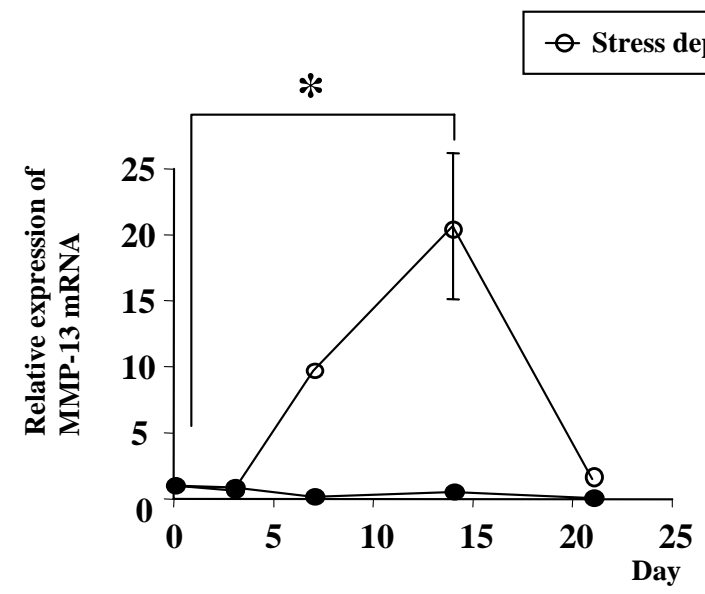

B

C
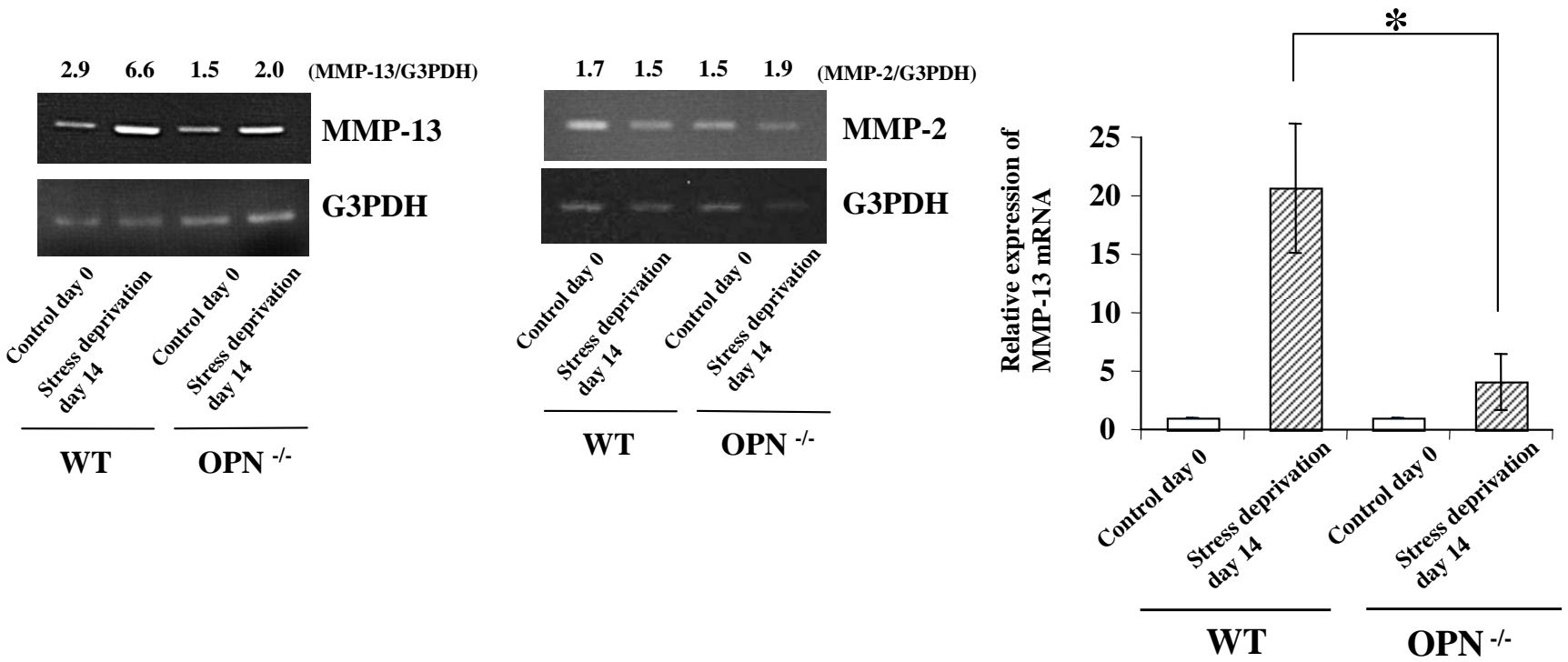
Figure 8

A

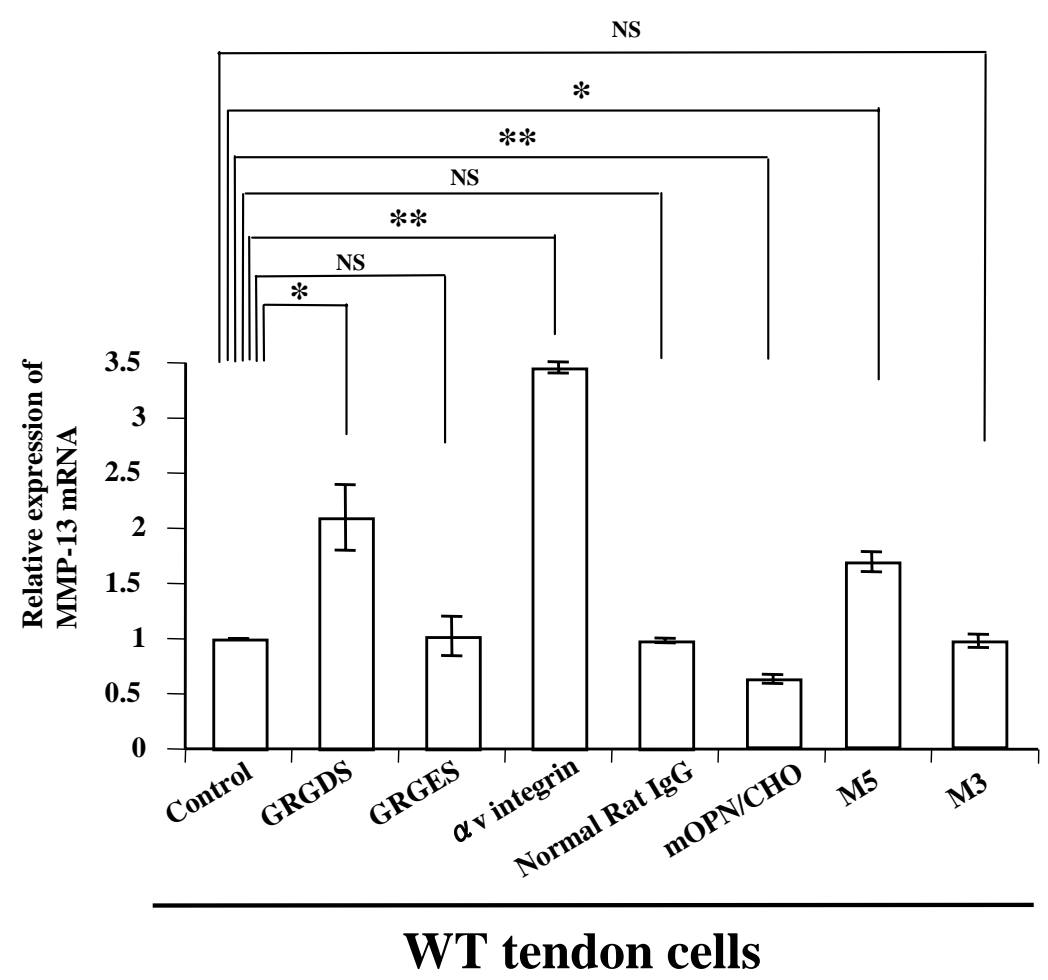

B

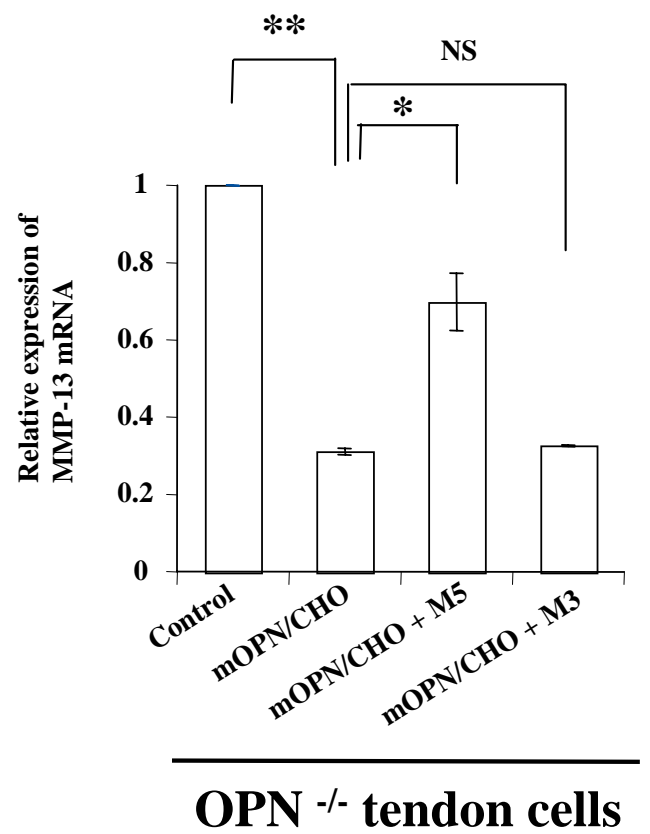

